\title{
Response of soil quality indicators and their spatial variability to land degradation in central Iran
}

\author{
M. Nael, H. Khademi*, M.A. Hajabbasi \\ Department of Soil Science, College of Agriculture, Isfahan University of Technology, Isfahan, Iran
}

Received 9 December 2002; received in revised form 24 May 2004; accepted 31 May 2004

\begin{abstract}
Studying land degradation through a soil quality approach, which reveals soil functioning within the ecosystem, is necessary for sustainable management of land resources. This investigation was conducted to understand the changes of soil functions, resulting from exploitive management, using some soil quality indicators and their statistical and geostatistical measures. Undisturbed and disturbed sites were identified in each of two study areas, including an oak forest and a semiarid rangeland in central Iran. Soil organic carbon (OC), total nitrogen (TN), microbial respiration (MR), aggregate stability (AS), and hydraulic properties of the sites were determined. Statistical comparisons of frequency distribution functions of OC and MR revealed that these functions are normal in protected forest, while in the disturbed forest distributions deviate from normality. In the rangeland sites, the results were exactly the opposite. Spatial variability of the two variables in forest sites demonstrated pure nugget and spherical pattern in protected and disturbed sites, respectively. As for the rangeland ecosystem, pure nugget pattern was observed for both sites. According to our findings, protection of rangeland has resulted in higher OC and MR with no effect on the amount of $\mathrm{TN}$ and infiltration rate. The negative effect of this management system was a decrease in aggregate stability due to the formation of crust as a result of complete grazing exclusion. By contrast, improvement in all soil quality indicators in protected forest indicated the success of conservative management in this region.
\end{abstract}

(c) 2004 Elsevier B.V. All rights reserved.

Keywords: Soil quality; Soil degradation; Semiarid rangeland; Oak forest; Geostatistics; Central Iran

\section{Introduction}

Past management of agricultural and terrestrial ecosystems to meet the needs of increasing human population has taxed the capacity and resilience of soil and ecosystem functions to maintain the global balance of energy and matter (Doran, 1999). Deforestation, overgrazing, and conversion of rangelands and forests have resulted in a great decline in the physical, chemical, and biological quality of soil re-

\footnotetext{
* Corresponding author. Fax: +98 3113912254.

E-mail address: hkhademi@cc.iut.ac.ir (H. Khademi).
}

sources in Iran (Hajabbasi et al., 1997), as well as elsewhere in the world (Doran et al., 1998).

Soil quality is defined as: "capacity of the soil to function, within the ecosystem and land-use boundaries, to sustain biological productivity, maintain environmental quality, and promote plant and animal health"; therefore, it is one of the most important factors in developing sustainable land management and sustaining the global biosphere (Doran and Parkin, 1994; Wang and Gong, 1998). If ecosystem processes are well understood, the sustainability of the system can be evaluated. Under such circumstances, soil quality assessment involves measuring the current state of 
an indicator and comparing the results with known or desired values (Karlen et al., 1997). Manley et al. (1995) applied this methodology to evaluate sustainability of different rangeland management systems by the response of $C$ and $N$ to grazing. Soil organic matter, soil porosity, and infiltration rate have recently been proposed by international groups as major soil quality indicators in forest soils (Doran et al., 1996; Elliot et al., 1999).

However, a high level of spatial variability in these indicators poses a serious limitation in using this approach. A mean value of a variable across all landscape units and vegetation microsites may not give an accurate indication of how good or otherwise soil quality is at a particular site. For example, Herrick and Whitford (1995) noted that average soil properties could be quite similar for annual grassland and for a shrubland, due to the canceling out effect of contrasting values from shrub and intershrub spaces. They presented some statistical measures that, in some cases, may serve as indicators of how well the soil is performing selected functions; these measures are: coefficient of variation $(\mathrm{CV})$, ratios between sampling strata such as the ratio of shrub versus shrub interspace soil properties, the scale at which variability occurs, and the shape of the frequency distribution. Schlesinger et al. (1990) suggested that spatial and temporal distribution of water, $N$ content, and other soil properties manifest the changes of ecosystem functions at the transition between arid and semiarid rangelands. This transition may result from direct human exploitation or indirect causes, such as global climate change. According to their hypothesis, when net, long-term desertification of a productive grassland occurs, a relatively uniform distribution of some soil quality indices is replaced by an increase in their spatial and temporal heterogeneity; which finally leads to the invasion of grasslands by shrubs. They suggested that accumulation of nutrients under desert shrubs, leading to the development of "islands of fertility", is an autogenic process that may promote the persistence of shrubs in the community, and the desertification of grasslands that are invaded by shrubs (Schlesinger and Pilmanis, 1998). Schlesinger et al. (1996) compared the scale of soil heterogeneity by calculation of semivariograms in different plant communities of the southwestern United States.

Evaluation of soil degradation in Iran is mainly limited to accelerated water erosion and almost no soil quality approach has been introduced and applied. This investigation was conducted to introduce some soil quality indicators potentially sensitive to land degradation in selected semiarid rangeland of Isfahan province and oak forest of Kohkiluye Boyerahmad province in central Zagrous (Iran).We studied the variability of these indices in general, and spatial variability of some in particular, in response to soil degradation.

\section{Materials and methods}

\subsection{Rangeland study area}

A twenty year protected research pasture at Hamzavi Station, located about $25 \mathrm{~km}$ east of Semirom $\left(31^{\circ} 8^{\prime} \mathrm{N}\right.$ and $\left.52^{\circ} 42^{\prime} \mathrm{W}\right)$, in Isfahan province, was selected as an undisturbed rangeland site (Fig. 1). The area is $2300 \mathrm{~m}$ above sea level with mean annual temperature and rainfall of $9{ }^{\circ} \mathrm{C}$ and $350 \mathrm{~mm}$, respectively. The natural vegetation includes Erotia ceratoides, Stipa barbata, Bromus tomentellus, Polygonum salicornoides, Scariola orientalis, Astrachanta sp., and Astragalus cyclophyllus. An overgrazed, formerly cultivated area near Hamzavi Station, exclusively covered by $S$. orientallis, was also selected as a disturbed rangeland site. An attempt was made to choose uniform fields in order to avoid anisotropic effects in the geostatistical analysis. The soil of both sites, developed on an alluvial plain with calcareous parent materials and overall slope of $2 \%$, is a Typic Calcixerepts (Soil Survey Staff, 1999). Table 1 summarizes some soil properties and estimated plant cover in these sites.

The disturbed site was in an area which was converted to dryland wheat farming about 30 years ago. After a few years, cultivation was abandoned, mostly due to low productivity, and since then, it has been used as rangland. In the last 25 years, the area has been degraded by intensive overgrazing.

Two sampling grids (a large and a small ) were used at each site (Fig. 2a); 64 soil samples $(0-15 \mathrm{~cm}$ depth) were collected from the large grid at $20 \mathrm{~m} \times$ $20 \mathrm{~m}$ intervals and 28 from the smaller grid at 3, 6, and $12 \mathrm{~m}$ intervals. Overlapping of one sampling point resulted in 91 data points for each site. For each point it was noted whether the sample was taken from beneath 


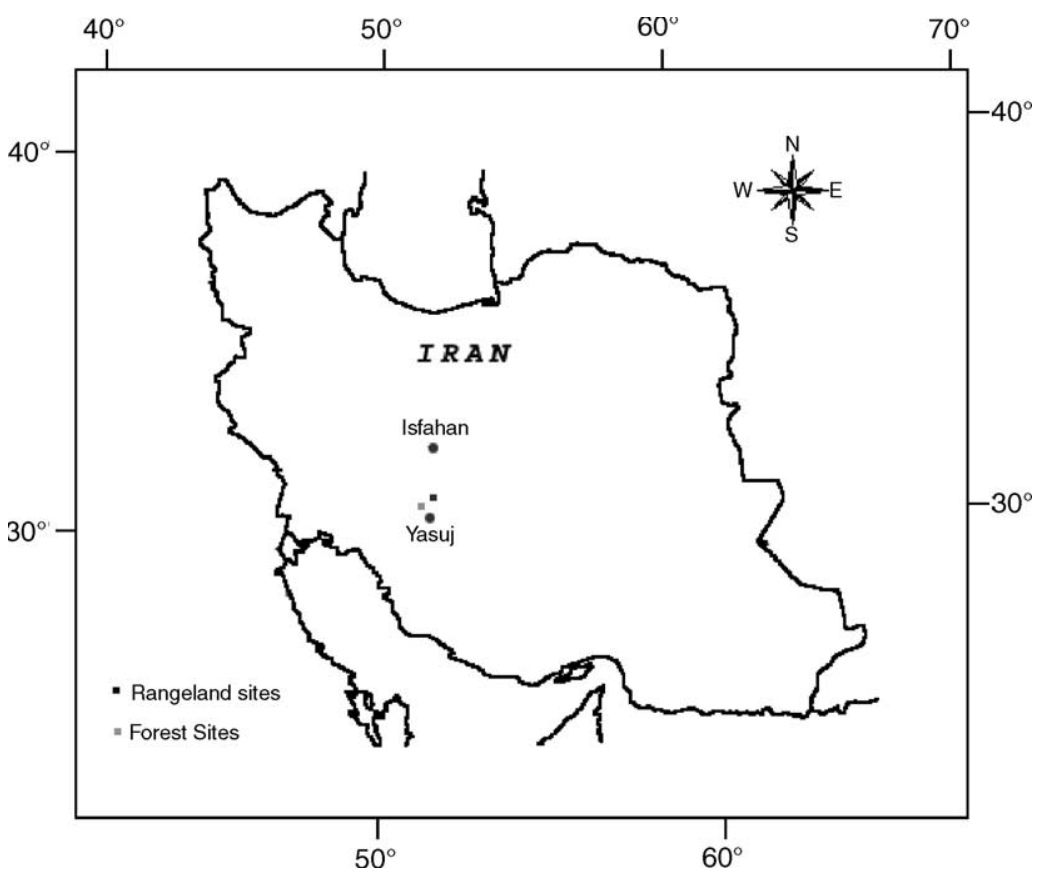

Fig. 1. Location of the study areas in Central Iran.

the vegetation or from bare soil between plants. The distance of each sample from the nearest plant species was measured.

\subsection{Forest study area}

Dena Reserved Forest, about $60 \mathrm{~km}$ northwest of Yasuj $\left(31^{\circ} 5^{\prime} \mathrm{N}\right.$ and $\left.51^{\circ} 17^{\prime} \mathrm{W}\right)$, in Kohkiluye Boyerahmad Province (Fig. 1) was selected as an undisturbed forest. The area is $2500 \mathrm{~m}$ above sea level with average yearly temperature and rainfall of $14.9^{\circ} \mathrm{C}$ and $500 \mathrm{~mm}$, respectively. The site is mainly covered with Quercus persica, Amygdalus scoparia, Amygdalus erioclada, Lonicera arborescence, Pistatia mot- ica, Crataegus spp., Popolus nigra, Tymus kotschianus, Astragalus sp., and some annual and perennial grasses. The soil is derived from calcareous parent material, occurring on round hills with a slope of 30-35\% and is classified as Typic Calcixerolls (Soil Survey Staff, 1999). Outside Dena Reserved Forest, where deforestation and cultivation have resulted in a degraded forest, the soil is classified as Typic Calcixerepts. This is only due to the decrease in mollic epipedon thickness, which is in turn due, presumably, to soil erosion. In this landscape, a sampling area similar to Dena forest, from the viewpoint of parent material, slope, and aspect, was selected as disturbed forest, with vegetation exclusively composed of $Q$. persica and Astra-

Table 1

Selected properties of surface soil $(0-15 \mathrm{~cm})$ and estimated plant cover in the different sites

\begin{tabular}{|c|c|c|c|c|c|}
\hline Land use & $\mathrm{pH}$ & $\mathrm{CaCO}_{3}(\%)$ & Texture & & \\
\hline PR & 7.8 & 14.2 & Silty clay loam & 38 & \\
\hline \multirow[t]{2}{*}{ DR } & 8.0 & 23 & Silty clay loam & 5 & \\
\hline & & & & Overstory & Understory \\
\hline PF & 7.9 & 14.1 & Silty clay loam & 48 & 30 \\
\hline DF & 7.8 & 40.5 & Loam & 18 & 9 \\
\hline
\end{tabular}

PR and DR: protected and disturbed rangeland, respectively; PF and DF: protected and disturbed forest, respectively. 


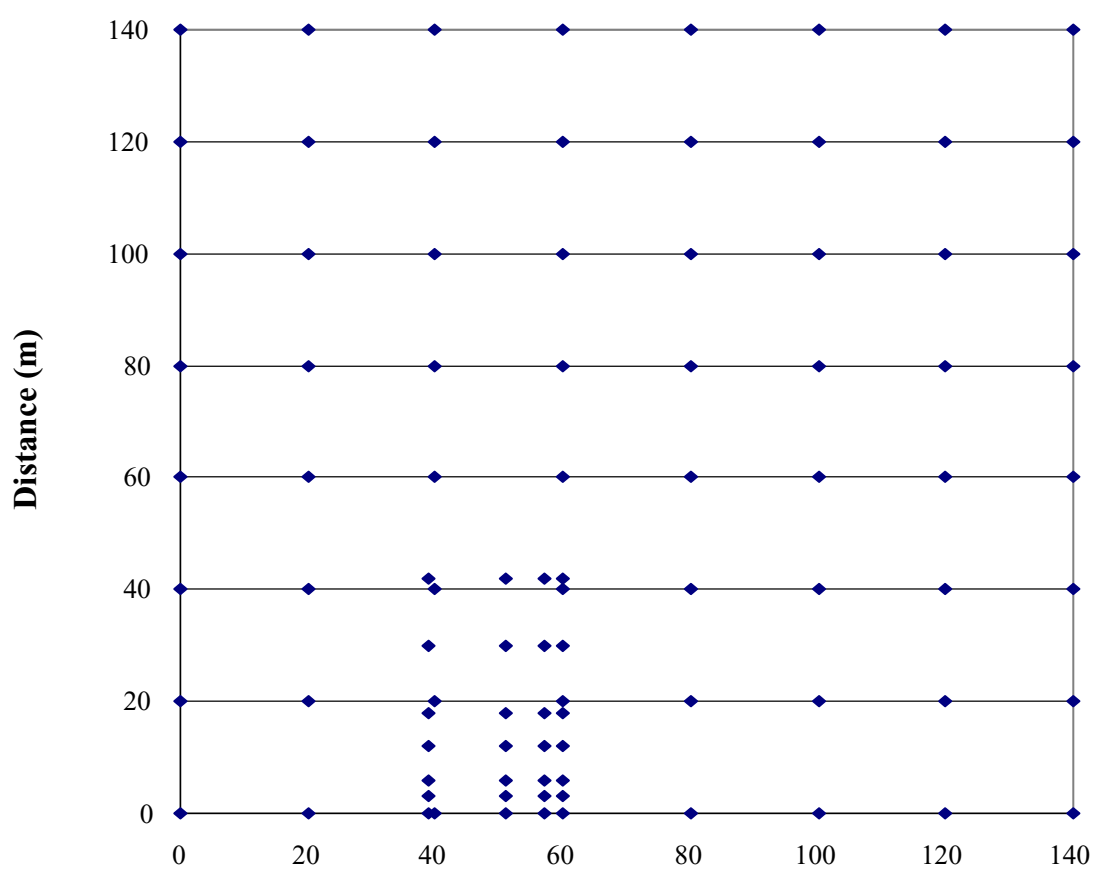

(a)

Distance (m)

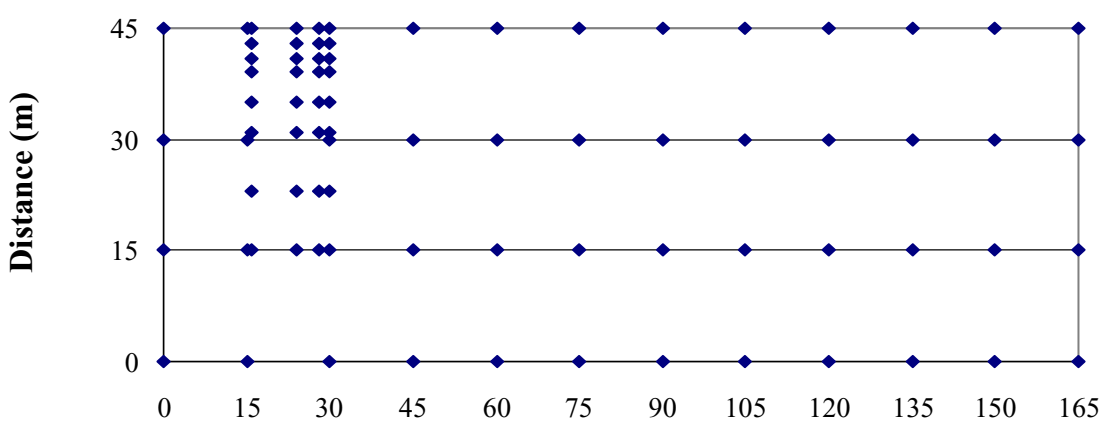

(b)

\section{Distance (m)}

Fig. 2. Soil sampling patterns: (a) in the rangeland sites, the large grid intervals are $20 \mathrm{~m} \times 20 \mathrm{~m}$ and the small grid consists of 3 , 6, and $12 \mathrm{~m}$ intervals; (b) in the forest sites, the large grid intervals are $15 \mathrm{~m} \times 15 \mathrm{~m}$ and the small grid consists of 2,4 , and $8 \mathrm{~m}$ intervals.

galus $\mathrm{sp}$. Table 1 summarizes some soil properties and estimated plant cover in these sites.

Deforestation in this area was carried out about three decades ago in order to provide extra land for dryland farming and to use the cut trees as fuelwood. Since deforestation, poor management practices with almost no conservation programs have caused severe land degradation.

Two sampling grids were used at each site (Fig. 2b); 48 soil samples $(0-15 \mathrm{~cm}$ depth) were collected from the large grid at $15 \mathrm{~m} \times 15 \mathrm{~m}$ intervals and 32 samples from the small grid at 2,4 , and $8 \mathrm{~m}$ intervals. Over- 
lapping of one sample point resulted in 79 data points. The position of each sample in relation to the nearest tree was documented.

\subsection{Laboratory and field analysis}

Soil organic carbon content (OC) was determined using a wet combustion method (Nelson and Sommers, 1982) and total nitrogen (TN) by the Kjeldahl method (Bremner and Mulvaney, 1982). Microbial respiration rate (MR) was measured by the closed bottle method of Anderson (1982) and aggregate stability was determined by the wet sieving method (Angers and Mehuys, 1993; Kemper and Rosenau, 1986) and expressed as mean weight diameter (MWD). Soil samples were passed through a $4.6 \mathrm{~mm}$ sieve, sprayed with water as a pretreatment and oscillated in water for $10 \mathrm{~min}$ using a set of sieves with $2,1,0.5$, and $0.25 \mathrm{~mm}$ apertures.

Soil infiltration rate (IR) was determined in the rangeland sites by the double ring method (Bouwer, 1986). The rings were 26 and $32 \mathrm{~cm}$ in diameter and the depth of insertion was $6-8 \mathrm{~cm}$. The measurement time ranged from 1.5 to $2 \mathrm{~h}$ when infiltration rate remained constant. This method was not applicable in the forest sites because of slope constraint; therefore, saturated hydraulic conductivity $\left(\mathrm{K}_{\mathrm{s}}\right)$ and soil bulk density (BD) of undisturbed core samples were measured in the laboratory (Klute and Dirksen, 1986).

Primary statistical analyses such as frequency distribution, normality tests and mean comparisons were conducted using SPSS (SPSS, 1998). Two-sample Kolmogrov-Smirnov and Mann-Whitney tests were used when the basic requirements for parametric statistics were violated. Calculation of experimental variograms and modeling of spatial variability of $\mathrm{OC}$ and MR were carried out by the Geo-Eas (Englund and Sparks, 1980) and Variowin programs (Pannatier, 1993).

\section{Results}

\subsection{Statistical description and comparison}

The summary statistics for the variables are given in Tables 2 and 3. The one-sample Kolmogrov-Smirnov test confirmed the normal distribution of OC and MR in the disturbed rangeland site while rejecting this model for the same variables in the protected site $(\alpha=0.05)$. The coefficient of variation $(\mathrm{CV})$, as an index of overall variation and, therefore, of heterogeneity of soil properties at each site, was higher for both variables in protected as compared to disturbed rangeland, suggesting dissimilarity of variables among the samples taken from the two sites (Table 2).

The frequency distribution models were quite different for the forest sites than for rangeland. Both variables (OC and MR) were normally distributed in the protected forest, while in the disturbed site, the same variables exhibited serious deviation from normality as indicated by skewness values (Table 2). The CV values for OC and MR were lower in protected than in disturbed forest, which indicates the homogeneity of soil quality indices in the reserved forest (Table 2). As

Table 2

Summary statistics for soil organic carbon and microbial respiration in the study sites

\begin{tabular}{|c|c|c|c|c|c|c|c|c|c|c|c|}
\hline Variable & Land use & $N$ & Mean & Median & Mode & Range & IQR & S.D. & $\mathrm{CV}$ & Skewness & Kurtosis \\
\hline \multirow[t]{4}{*}{ Organic carbon $(\%)$} & PR & 91 & $0.72^{\mathrm{a}}$ & 0.6 & 0.55 & 1.48 & 0.35 & 0.32 & 44 & 1.46 & 1.8 \\
\hline & DR & 91 & 0.45 & 0.43 & 0.34 & 0.58 & 0.15 & 0.11 & 24 & 1.4 & 2.8 \\
\hline & $\mathrm{PF}$ & 77 & $4.1^{\mathrm{a}}$ & 3.7 & 2.98 & 9.34 & 1.97 & 1.74 & 42 & 1.3 & 2.7 \\
\hline & DF & 77 & 1.67 & 1.56 & 1.57 & 5.05 & 0.74 & 0.84 & 50 & 2.8 & 11.2 \\
\hline \multirow[t]{4}{*}{ Microbial respiration ( $\mathrm{mg} \mathrm{CO}_{2} / \mathrm{g}$ day) } & PR & 90 & $0.23^{\mathrm{a}}$ & 0.2 & 0.13 & 0.68 & 0.15 & 0.14 & 62 & 1.6 & 2.4 \\
\hline & DR & 83 & 0.15 & 0.15 & 0.15 & 0.22 & 0.07 & 0.05 & 28 & 0.59 & -0.005 \\
\hline & $\mathrm{PF}$ & 77 & $0.41^{\mathrm{a}}$ & 0.36 & 0.32 & 0.94 & 0.22 & 0.19 & 46 & 0.82 & 0.48 \\
\hline & DF & 76 & 0.19 & 0.16 & 0.14 & 0.8 & 0.07 & 0.13 & 68 & 3.1 & 11.8 \\
\hline
\end{tabular}

$N$ : number of samples; IQR: interquartile range; PR and DR: protected and disturbed rangeland, respectively; PF and DF: protected and disturbed forest, respectively.

${ }^{\mathrm{a}}$ Indicates significant differences $(P<0.001)$ between pairs of sites. 
Table 3

Statistical comparisons of selected soil quality indices in the study sites

\begin{tabular}{|c|c|c|c|c|c|c|c|c|c|c|c|c|c|c|c|}
\hline \multirow[t]{2}{*}{ Land use } & \multicolumn{3}{|c|}{$\mathrm{TN}(\%)$} & \multicolumn{3}{|c|}{ MWD (mm) } & \multicolumn{3}{|c|}{ IR $(\mathrm{mm} / \mathrm{min})$} & \multicolumn{3}{|c|}{$\mathrm{Ks}(\mathrm{cm} / \mathrm{min})$} & \multicolumn{3}{|c|}{$\mathrm{BD}\left(\mathrm{g} / \mathrm{cm}^{3}\right)$} \\
\hline & $N$ & Mean & $\mathrm{CV}$ & $N$ & Mean & $\mathrm{CV}$ & $N$ & Mean & $\mathrm{CV}$ & $N$ & Mean & $\mathrm{CV}$ & $N$ & Mean & $\mathrm{CV}$ \\
\hline PR & 9 & $0.1^{\mathrm{ns}}$ & 30 & 26 & $0.35^{*}$ & 20 & 4 & $0.23^{\mathrm{ns}}$ & 35 & & - & & & - & \\
\hline DR & 5 & 0.08 & 3 & 14 & 0.39 & 13 & 4 & 0.25 & 48 & & - & & & - & \\
\hline $\mathrm{PF}$ & 5 & $0.83^{* * *}$ & 130 & 73 & $0.88^{* * *}$ & 60 & & - & & 15 & $0.46^{* * *}$ & 35 & 8 & $0.99^{* * *}$ & 9 \\
\hline DF & 5 & 0.15 & 40 & 31 & 0.34 & 47 & & - & & 12 & 0.21 & 76 & 6 & 1.28 & 5 \\
\hline
\end{tabular}

$N$ : number of samples; PR and DR: protected and disturbed rangeland, respectively; PF and DF: protected and disturbed forest, respectively; ns: not significant differences.

${ }^{*} P<0.05$ for comparisons between pairs of sites.

*** $P<0.001$ for comparisons between pairs of sites.
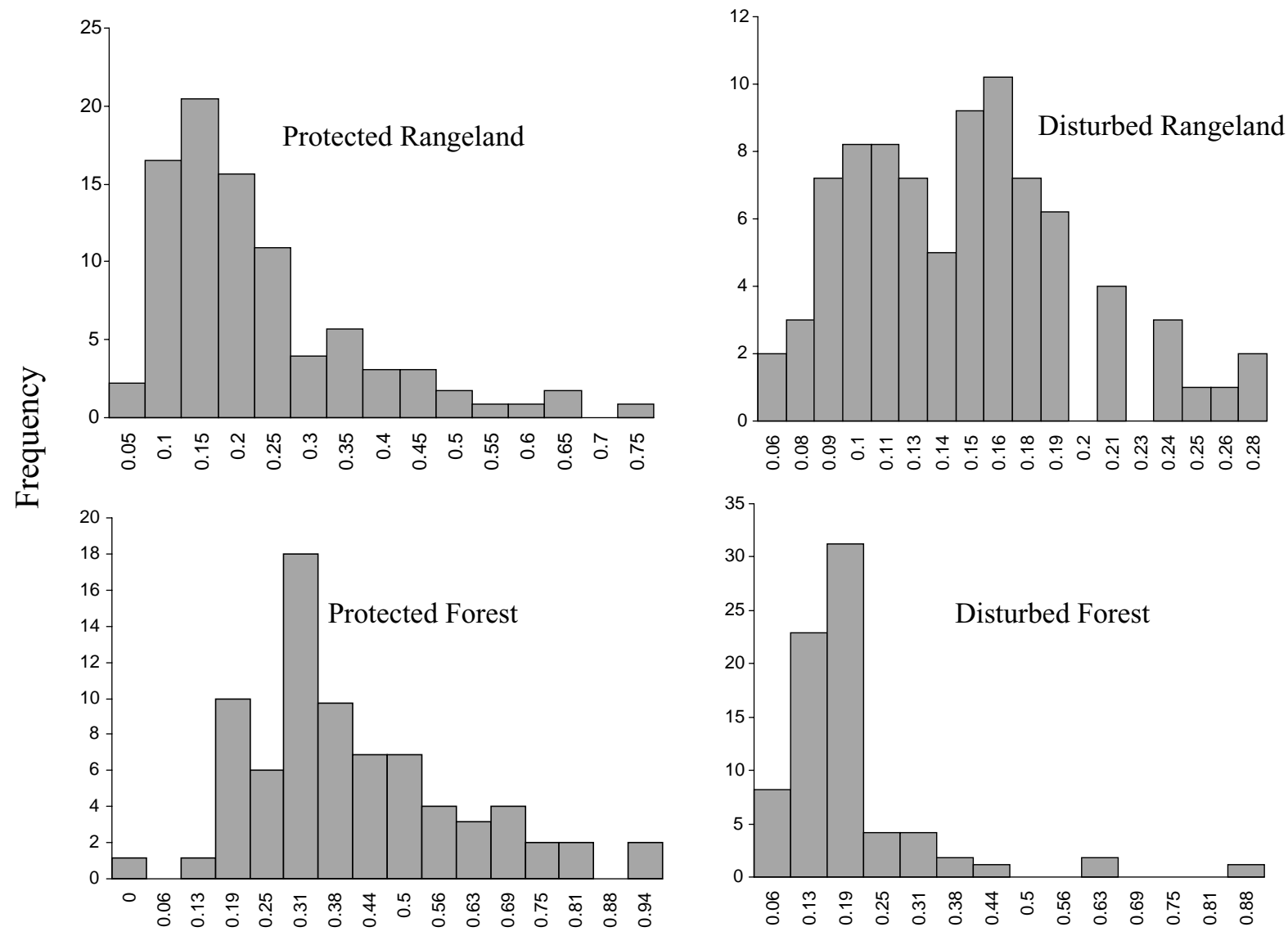

Microbial Respiration (mg $\mathrm{CO}_{2} /$ g.day)

Fig. 3. The frequency distribution for soil microbial respiration rate values in the different sites. 
Table 4

Ratio of the mean soil quality indices measured under vegetation to those between vegetation

\begin{tabular}{llll}
\hline Land use & OC & MR & MWD \\
\hline PR & $1.56^{* * *}$ & $1.75^{* * *}$ & $1.2^{*}$ \\
DR & NA & NA & NA \\
PF & $1.31^{* *}$ & $1.16^{\text {ns }}$ & $1.57^{* * *}$ \\
DF & $1.72^{* * *}$ & $2.47^{* * *}$ & $1.42^{* *}$ \\
\hline
\end{tabular}

PR and DR: protected and disturbed rangeland, respectively; PF and DF: protected and disturbed forest, respectively; NA indicates not applicable; ns: not significant differences.

${ }^{*} P<0.05$ for comparisons between sampling strata.

** $P<0.01$ for comparisons between sampling strata.

*** $P<0.001$ for comparisons between sampling strata.

an example, the ferquency distribution of MR values for all the sites are shown in Fig. 3.

Dissimilarity of frequency distribution of the variables in different sites, deviation from normality in some cases, and finally, insufficient knowledge of the distribution model for some soil variables (Tables 2 and 3), violated the basic assumptions of parametric statistical tests and justified the use of non-parametric tests for all variables. In rangeland sites, organic carbon and microbial respiration were significantly higher in the protected than in the disturbed site $(P<0.001)$ (Table 2). No significant difference was observed between the two sites for total nitrogen and infiltration rate $(P<0.05)$. In contrast, the mean diameter of water stable aggregates was higher in the disturbed site $(P<0.001)$ (Table 3). In the forest sites, OC, MR, $\mathrm{MWD}$, and $\mathrm{K}_{\mathrm{s}}$ were significantly higher in the protected site, while BD was lower in this site, compared to the disturbed site $(P<0.001)$ (Tables 2 and 3$)$.

Mean values of all variables were also compared by parametric $t$-tests and similar results were observed with the exception of TN in the forest sites, which did not exhibit any significant difference between the two sites. This reveals that, the great difference in variance of TN (Table 3) is beyond the "small deviations", tolerable for the use of parametric tests.

The values for OC, MR, and MWD were significantly higher in samples taken under vegetation as compared to the bare soil between plant species in the protected rangeland. In disturbed rangeland, because of complete removal of vegetation and subsequent tillage, all samples were taken from the bare soil (Table 4). In contrast, the high values of soil quality variables were more concentrated under forest trees in the disturbed forest than in the protected site. An exception for this generalization is the MWD index, for which the ratio is slightly higher in protected forest (Table 4).

\subsection{Geostatistical variability of soil quality attributes}

Log transformed variables (ln X) exhibited normal distribution for OC and MR for all types of land use; therefore, experimental semivariograms were calculated upon the transformed data. Anisotropy did not appear to be present and the best isotropic variogram models were fitted by the cross validation method (Nielson and Alemi, 1989). For protected forest, a pure nugget model was fitted to the semivariograms of OC and MR (Fig. 4). This model indicates randomly distributed data pattern and suggests that the changes in semivariance $(\gamma)$ with increasing lag distance are not significant and the total variance is found at all scales of sampling. In other words, there is no spatial dependence in the data points (Oliver and Webster, 1991). The nugget variance was 0.164 and 0.174 for OC and MR, respectively.

For the disturbed forest, a spherical model provided a significant fit to semivariograms of $\mathrm{OC}$ and MR (Fig. 4). This model suggests that these variables are spatially patterned and that the semivariance $(\gamma)$ first rises and then levels off at the sill, indicating the distance beyond which samples are independent. Other features of this model are range and nugget; the former indicates the range over which samples show spatial dependence and the latter is the variance that exists at scales finer than the field sampling which is found at zero lag distance. In this site, OC and MR are autocorrelated over distances of 46.5 and $42.8 \mathrm{~m}$, respectively. Nugget to sill ratio, which indicates the magnitude of random pattern among the data (Trangmar et al., 1985), was 0.01 and 0.2 for the respective variables. These values indicate that, for OC, $1 \%$ of the variance is found at distance $<2 \mathrm{~m}$, and the remaining variance is found over a $46.5 \mathrm{~m}$ range of autocorrelation. For MR, the spatial structure describes $80 \%$ of variation.

For the rangeland area, a pure nugget model was fitted to semivariograms of OC and MR in both sites (Fig. 5), suggesting the absence of autocorrelation among samples. 
Protected Forest

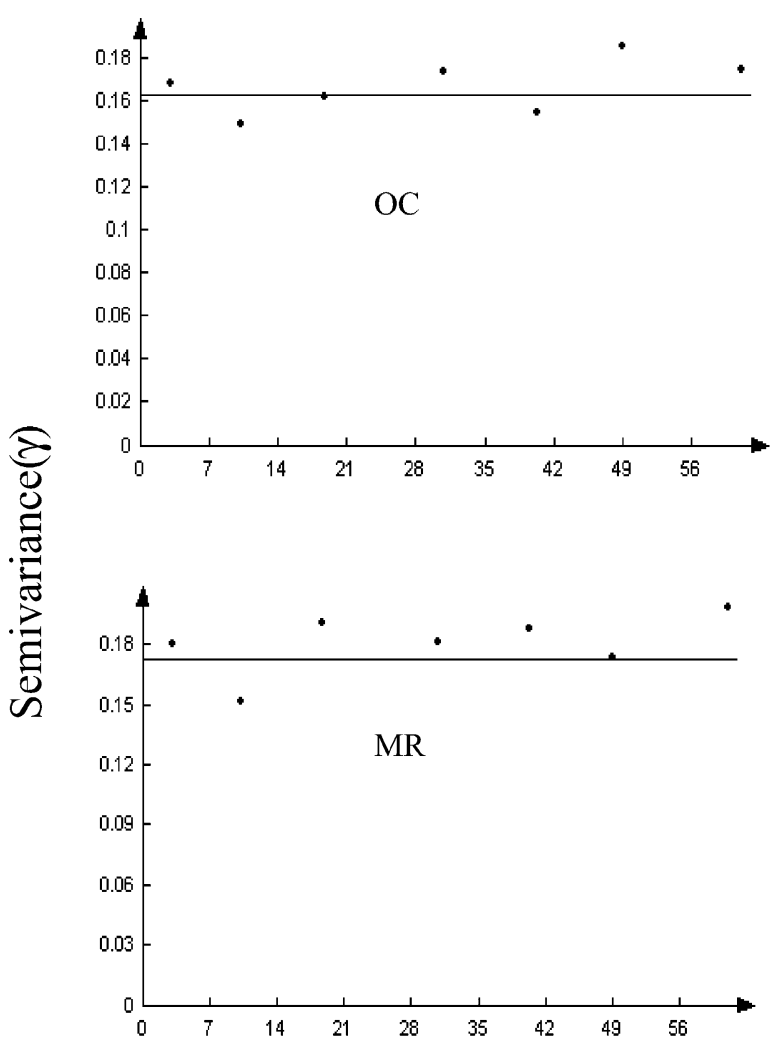

Disturbed Forest
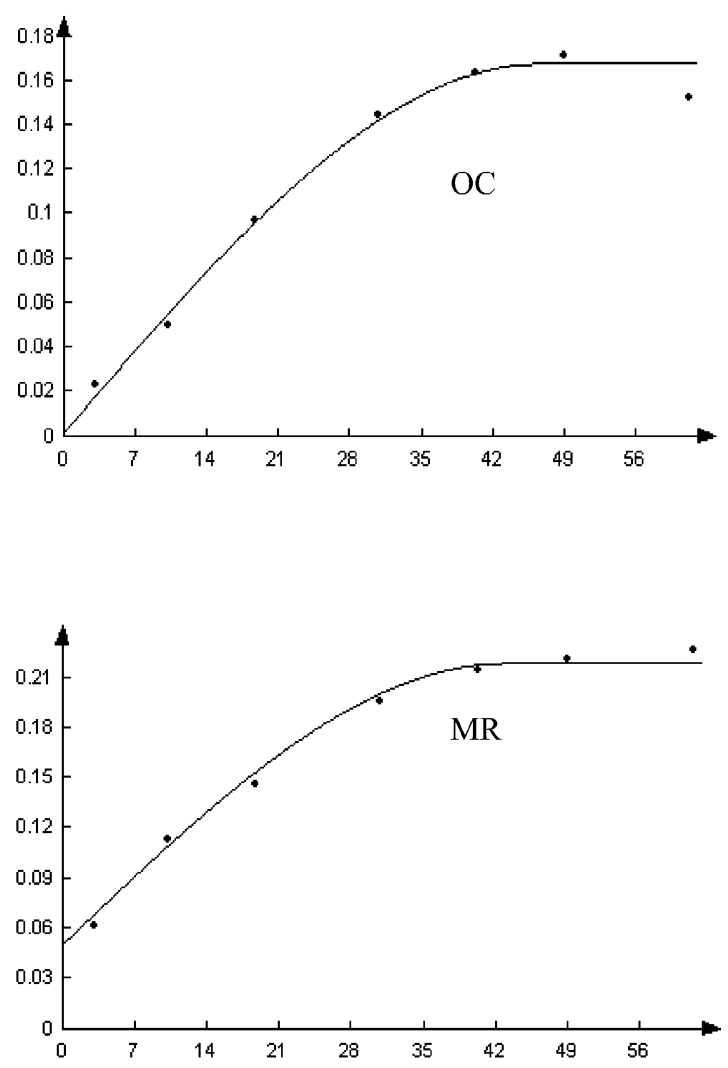

Lag Distance (m)

Fig. 4. The effect of soil degradation on spatial variability of organic carbon (OC) and microbial respiration rate (MR) in the forest sites.

\section{Discussion}

Soil degradation has a great influence on the frequency distribution models of soil quality indicators. Normal distributions of OC and MR in the protected forest reveal homogeneity and random distribution of the variables in this site. It could be said that these two variables, determined directly by biological influences, have a great degree of central tendency, which means that the data in question are concentrated around the mean values of the sample population. This observation could be explained by the effective presence of overstory and understory vegetation in this area. In other words, OC and MR are mainly controlled by biotic factors that act similarly throughout the area. This means that almost all samples have been collected from an area homogenized by the biotic influences. By contrast, with the drastic removal of vegetation, most samples are being taken from bare soil where biotic factors have reduced influence. Therefore, OC and MR values in disturbed forest tend to be centered on small observations, resulting in a positive skewness of the variables.

The fact that inverse results, namely skewed distribution in the protected and normal distribution in the disturbed site, were observed in the rangeland sites is quite meaningful. As other results demonstrate (Table 4), the situation of protected rangeland is not comparable with that of protected forest. In fact, the reserved Hamzavi Station is not really a grassland, it has the characteristics of a shrubland (Table 4), hence the variables have a positively skewed distribution. 

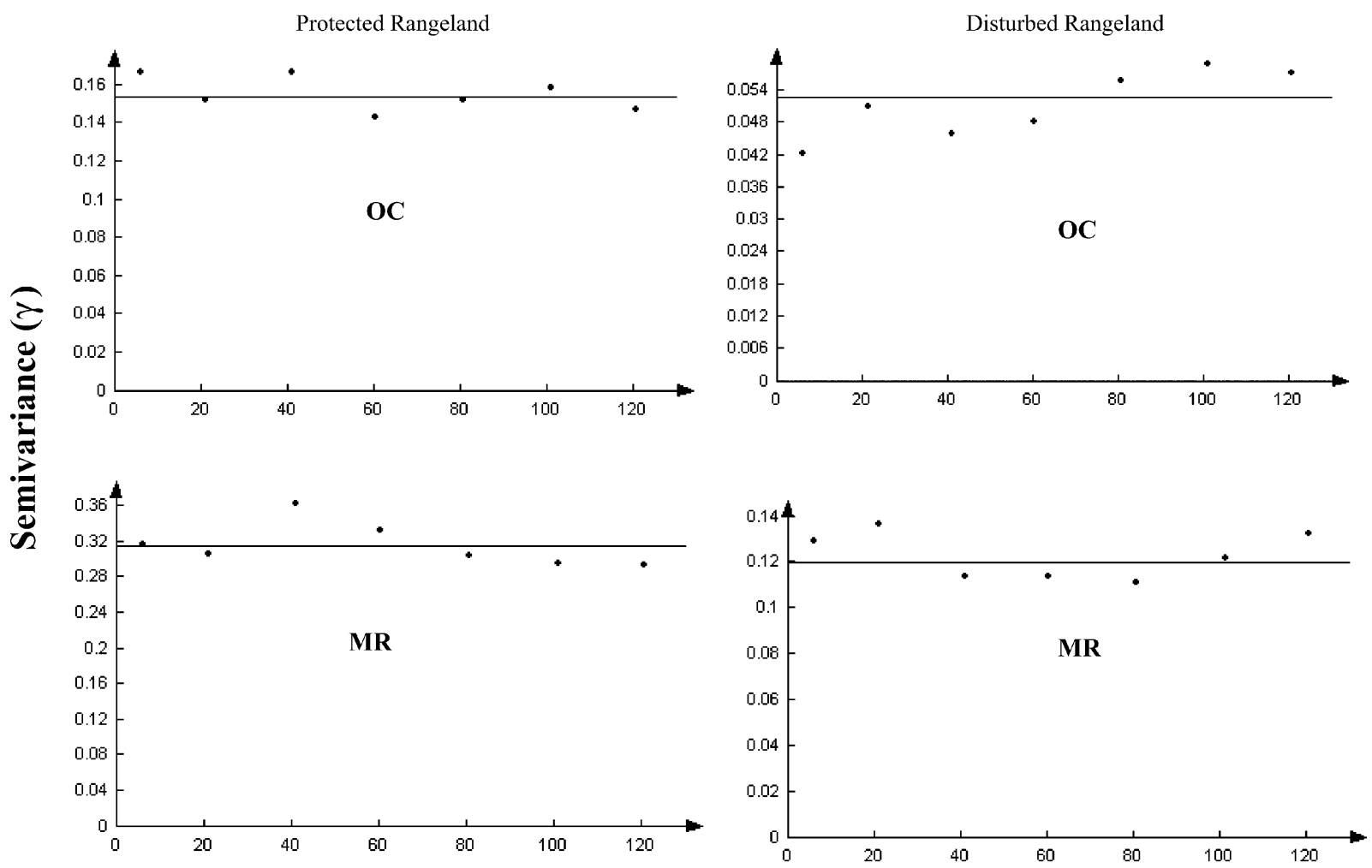

\section{Lag Distance (m)}

Fig. 5. The effect of soil degradation on the spatial variability of organic carbon (OC) and microbial respiration rate (MR) in the rangeland sites.

The disturbed rangeland is almost devoid of any vegetation, therefore almost all samples were taken from bare soil. This shows the strong central tendency, i.e. normal distribution model, of the variables. It is hypothesized that in a real grassland, many soil variables tend to conform to the normal distribution models because of the homogenizing influences of biotic factors (Schlesinger et al., 1990) while replaced shrubland does not exhibit this quality. Combining this principle with our findings, one can conclude that further degradation of a shrubland ecosystem could restore the frequency distribution model of selected soil quality indicators to their initial mode, so that the extreme stages will have the same characteristics; This may suggest the maxim of "Extremes Meet". But it goes without saying that this similarity does not pertain to the absolute values of these variables as will be discussed later.
The fundamental transformation of spatial pattern, from pure nugget in the protected to spherical in the disturbed site, of OC and MR due to forest land degradation (Fig. 4), is unquestionably related to the drastic removal of vegetation and its unavoidable consequences. In protected forest, OC and MR are spatially independent at the studied scale. This is due to the homogenized character of this ecosystem, caused by biotic factors, as discussed above. When the vegetation is substantially removed, the effective contribution of biotic factors to soil variables and their spatial variability is diminished. As a consequence, abiotic factors, in this case topography, especially undulation and high slope, determine and, in turn, introduce the new spatial structure of the variables. The spherical model fitted to the semivariograms of this site shows that $\mathrm{OC}$ and MR are spatially auotocorrelated over the distance of 46.5 and $42.8 \mathrm{~m}$, respectively, which is in conformity 
with the undulating character of the studied landscape. It is important to note that this spherical model does not manifest directly the effect of individual plants on spatial variability of soil variables because of the nature of our sampling design which furnishes too few data pairs for short lags. However, it reveals the influence of vegetation indirectly as discussed above. Land degradation has not changed the spatial structure of the two variables in the rangeland. The best model is pure nugget for both protected and disturbed sites. In a fine-scale study of soil spatial variability, conducted in Chihuahuan Desert of New Mexico, Schlesinger et al. (1996) found that in grassland, 35-76\% of the variation in soil $N$ occurred at distances $<20 \mathrm{~cm}$ and the remaining variance was found over distances extending to $7 \mathrm{~m}$. In adjacent shrublands, soil $N$ was more concentrated under shrub and autocorrelated over distances extending 1-3 m, similar to mean shrub size reflecting local nutrient cycling by shrubs. In the present investigation, the observations could be explained firstly by the fact that our sampling plan could not detect the spatial variability of soil variables that may be caused by individual plants. Secondly, the role of topography on spatial variability of soil variables, contrary to the forest case, is not determinative in this landscape when vegetation is removed.

The content of OC and MR has increased due to grazing exclusion in the rangeland site, but this management has not affected TN, mainly because of past application of $N$ fertilizer to the cultivated, disturbed site. Since the application of manure is not a usual practice in the region, its contribution to soil OC content is negligible. Similarly, Gallardo and Schlesinger (1992) found that overgrazing and, as a consequence, the invasion of semiarid grasslands by shrubs decrease soil $C / N$ ratio due to the fact that the proportional loss of soil organic matter exceeds that for soil nitrogen and that carbon becomes limiting for microbial biomass which, in turn, leads to further desertification of this ecosystem. They reported that high levels of microbial biomass, manifested by high rates of nitrogen mineralization and nitrification, are found under shrub compared to barren shrub interspace. These microbial processes have the potential to produce gaseous by-products that are lost to the atmosphere. However, they believe that, in many cases, the shrub may act to conserve nitrogen by its immobilization in the litter and microbial biomass of mounds.
Non-insignificant difference in hydraulic conditions between the two sites could be explained by the fact that infiltration rate is an indicator of historic disturbance (Herrick et al., 1999). In other words, reestablishment of the rangeland has not influenced long-term soil quality indicators. Nonetheless, it is notable that the initial infiltration rate in the disturbed site $(2.2 \mathrm{~mm} / \mathrm{min})$ was slightly higher than that in the protected site $(1.8 \mathrm{~mm} / \mathrm{min})$ because of destruction of the surface seal caused by grazing and cultivation. Soil crust destruction would result in rapid initial infiltration, but it has no effect on final infiltration rate. Therefore, complete grazing exclusion has encouraged the process of crust formation in intershrub spaces; this explains the significant decrease in aggregate stability of bare soil (Table 4), in the protected in comparison with the disturbed site (Table 3). Parallel investigations on growth condition of dominant species of the region showed that the maximum growth of E. ceratoides is maintained under controlled grazing management, where crust formation is inhibited, not under complete grazing exclusion (Khademi, 1992).

The significant change in selected soil quality indices in forest sites reveals the drastic decrease in land quality caused by conventional management. It is suggested that the mean values of these indices in the protected site could be used as referred threshold values for further investigations in the region. Hajabbasi et al. (1997) found that deforestarion and subsequent tillage practices in Lordegan, Iran, had resulted in almost a $20 \%$ increase in bulk density, $50 \%$ decrease in organic matter, and a 10-15\% decrease in soluble ions comparing to the undisturbed forest soil. They applied tilth index coefficient as an integrated indicator of soil quality in their studied area.

\section{Conclusion}

Among the studied soil attributes in rangeland, OC, MR, and AS are reliable indicators of soil quality. Infiltration rate could not reveal short-term changes in soil functioning. Total nitrogen, as a soil quality indicator, is misleading in this ecosystem and may produce unrealistic interpretations. Although the rangeland conservation program has improved some fundamental aspects of soil quality in the area studied, but through this strategy, soil functioning is 
being restricted in some respects and it is likely that controlled grazing management best promotes ideal soil functioning. All attributes studied in the forest sites are useful indicators of soil quality and the corresponding mean values are presented as guidelines for evaluating management change. Frequency distribution functions of the selected biological variables and their spatial variability are mainly determined by soil degradation but the degree of land deterioration and the physical features of the ecosystem have a modifying influence on these statistical measures.

\section{Acknowledgements}

The authors would like to thank Isfahan University of Technology for financially supporting this study. We gratefully appreciate Isfahan Natural Resource Administration for their assistance and instructions. Comments on an earlier version of this paper by two anonymous reviewers and the editor are greatly appreciated.

\section{References}

Anderson, J.P.E., 1982. Soil respiration. In: Miller, R.H., Keeney, D.R. (Eds.), Methods of Soil Analysis, Part 2: Chemical Analysis. Soil Science Society of America, Madison, WI, pp. 831-872.

Angers, D.A., Mehuys, G.R., 1993. Aggregate stability to water. In: Carter, M.R. (Ed.), Soil Sampling and Methods of Analysis. Lewis Publishers, Boca Raton, pp. 651-657.

Bouwer, H., 1986. Intake rate: cylinder infiltrometer. In: Klute, A. (Ed.), Methods of Soil Analysis, Part 1: Physical Analysis. Soil Science Society of America, Madison, WI, pp. 825-844.

Bremner, J.M., Mulvaney, C.S., 1982. Nitrogen total. In: Buxton, D.R. (Ed.), Methods of Soil Analysis, Part 2: Chemical Analysis. American Society of Agronomy Inc. and Soil Science Society of America Inc., Madison, WI, pp. 595-624.

Doran, J.W., 1999. Soil health and global sustainability: translating science into practice. In: Proceedings of International Workshop on Soil Quality as an Indicator of Sustainable Land Management. Goulandris Natural History Museum. Gaia Environmental Research and Education Center, Athens, Greece, p. 7.

Doran, J.W., Parkin, T.B., 1994. Defining and assessing soil quality. In: Doran, J.W., Coleman, D.C., Bezdicek, D.F., Stewart, B.A. (Eds.), Defining Soil Quality for a Sustainable Environment. Soil Sci. Soc. Am. Special Publication 35, 3-21.

Doran, J.W., Leibig, M., Santana, D.P., 1996. Soil health and sustainability. Adv. Agron. 56, 1-56.
Doran, J.W., Leibig, M., Santana, D.P., 1998. Soil health and global sustainability. In proceedings of 16th World Congress of Soil Science, Montpellier, France, pp. 20-26 August.

Elliot, W.J., Page-Dumroeses, D., Robichaud, R., 1999. The effect of forest management on erosion and soil productivity. In: Lal, R. (Ed.), Soil Quality and Soil Erosion. Soil and Water Conservation Society and CRC Press, Boca Raton, pp. 195-208.

Englund, E., Sparks, A., 1980. Geo-Eas. USEPA. 60014-88/33.

Gallardo, A., Schlesinger, W.H., 1992. Carbon and nitrogen limitations of soil microbial biomass in desert ecosystems. Biogeochemistry 28, 55-68.

Hajabbasi, M.A., Jalalian, A., Karimzadeh, H.R., 1997. Deforestation effects on soil physical and chemical properties, Lordegan, Iran. Plant Soil 190, 301-308.

Herrick, J.E., Whitford, W.G., 1995. Assessing the quality of rangeland soils: challenges and opportunities. J. Soil Water Conserv. 50, 237-242.

Herrick, J.E., Weltz, M.A., Reeder, J.D., Schuman, G.E., Simanton, J.R., 1999. Rangeland soil erosion and soil quality: Role of soil resistance, resilience, and disturbance regime. In: Lal, R. (Ed.), Soil Quality and Soil Erosion. Soil and Water Conservation Society and CRC Press, Boca Raton, pp. 209-233.

Karlen, D.L., Mausback, M.J., Doran, J.W., Cline, R.G., Harris, R.F., Schuman, G.E., 1997. Soil quality: a concept, definition and framework for evaluation. Soil Sci. Soc. Am. J. 61, 4-10.

Kemper, W.D., Rosenau, R.C., 1986. Aggregate stability and size distribution. In: Klute, A. (Ed.), Methods of Soil Analysis, Part 1: Physical Analysis. Soil Science Society of America, Madison, WI, pp. 425-442.

Khademi, H., 1992. Soil survey report of Hamzavi Reserve Station, Hanna, Semirom, “(in Persian)”. Jahade' Sazandegi, Isfahan, Iran, $32 \mathrm{pp}$.

Klute, A., Dirksen, C., 1986. Hydraulic conductivity and Diffusivity: laboratory methods. In: Klute, A. (Ed.), Methods of Soil Analysis, Part 1: Physical Analysis. Soil Science Society of America, Madison, WI, pp. 687-734.

Manley, J.T., Schuman, G.E., Reeder, J.D., Hart, R.H., 1995. Rangeland soil carbon and nitrogen responses to grazing. J. Soil Water Conserv. 50, 294-298.

Nelson, D.W., Sommers, L.E., 1982. Total carbon, organic carbon, and organic matter. In: Buxton, D.R. (Ed.), Methods of Soil Analysis, Part 2: Chemical Analysis. American Society of Agronomy Inc. and Soil Science Society of America Inc., Madison, WI, pp. 539-579.

Nielson, D.R., Alemi, M.H., 1989. Statistical opportunities for analyzing spatial heterogeneity of field soils. Plant Soil 115, 285-296.

Oliver, M.A., Webster, R., 1991. How geostatistics can help you. Soil Use Manag. 7 (4), 206-217.

Pannatier, Y., 1993. Variowin: Software for spatial data analysis in 2D. Springer-Verlag, New York, p. 99.

Schlesinger, W.H., Pilmanis, A.M., 1998. Plant-soil interactions in desert. Biogeochemistry 42, 169-187.

Schlesinger, W.H., Reynolds, J.E., Cunningham, G.L., Huenneke, L.F., Jarrell, W.M., Virginia, R.A., Whitford, W.G., 1990. Biological feedbacks in global desertification. Science 247, 1043-1048. 
Schlesinger, W.H., Raikes, J.A., Hartley, A.E., Cross, A.F., 1996. On the spatial patterns of soil nutrients in desert ecosystems. Ecology 77 (2), 364-374.

Soil Survey Staff, 1999. Soil taxonomy: A basic system of soil classification for making and interpreting soil surveys. USDA Handbook No. 436, 2nd ed., Goverment Printing Office, Washington DC, p. 869.
SPSS for Windows, 1998. Rel. 9.0.0. Chicago, SPSS Inc. Trangmar, B.B., Yost, R.S., Uehara, G., 1985. Application of geostatistics to spatial studies of soil properties. Adv. Agron. $38,45-93$.

Wang, X., Gong, Z., 1998. Assessment and analysis of soil quality changes after eleven years of reclamation in subtropical China. Geoderma 81, 339-355. 